\title{
CHILE-JAPÓN, 1990-2007: AVANCES Y REPLIEGUES EN UNA ALIANZA ESTRATÉGICA FALLIDA
}

\author{
CHILE-JAPAN, 1990-2007: ADVANCES AND REFLECTIONS \\ IN A FAILED STRATEGIC ALLIANCE
}

César Ross*

\begin{abstract}
En este período histórico las relaciones bilaterales estuvieron marcadas por la decisión público-privada de otorgarles un estatus de "estratégicas", un esfuerzo bilateral que se vio frustrado tanto por lo complejo del objetivo que se planteaba como por lo extemporáneo del modelo de asociación al que apelaba (propio de la Guerra Fría), y que en el período 1990-2007 se vio enfrentado a la frenética velocidad de la transformación económica global.

Una pregunta clave para entender esta paradoja es ¿por qué una potencia como Japón decide tener una relación estratégica con un país tan pequeño como Chile? y eventualmente ¿qué ocurre cuando una potencia se acopla estratégicamente con un Estado más pequeño?

Para abordar este dilema, se utilizó dos metodologías analíticas elaboradas ex profeso y a partir de sus resultados se puede plantear una nueva idea que puede mejorar la comprensión de este fenómeno y, por extensión, de este período.

La hipótesis de este trabajo plantea que el subvalorado efecto de la crisis asiática de 1997 en el curso del acuerdo de alianza estratégica suscrito en 1994 puso en jaque el proyecto y que los esfuerzos posteriores por suscribir un TLC no lograron revertir.

Palabras claves: Chile, Japón, agenda, visitas, relaciones internacionales.
\end{abstract}

In this historical period, bilateral relations were marked by the public-private decision to grant them a status of "strategies." A bilateral effort that was frustrated by the complete objective that was posted as by the extemporaneous model of the association that appealed (typical of the cold war), and that from 1990 to 2007 was faced with the frenetic speed of global economic transformation. A fundamental question to understand this paradox is why a power like Japan decides to have a strategic relationship with a country as small as Chile? And eventually, what happens when a new power is strategically coupled with a smaller state?

To address this dilemma, we used two analytical methodologies elaborated ex profeso, and from their results, we can propose a new idea that can improve the understanding of this phenomenon, and by extension, of this period.

The hypothesis of this paper suggests that the undervalued effect of the 1997 Asian crisis in the course of the strategic alliance agreement signed in 1994 put the project in check and that subsequent efforts to sign a TCL failed to reverse.

Key words: Chile, Japan, agenda, visits, international relations.

\section{Introducción}

Quizá en ningún otro período histórico como en este las relaciones bilaterales estuvieron marcadas por la decisión público-privada de otorgarles un estatus de "estratégicas", un esfuerzo bilateral que se vio frustrado tanto por lo complejo del objetivo como por lo extemporáneo del modelo de asociación, al que apelaba (propio de la Guerra Fría) y que en el período 1990-2007 se vio enfrentado a la frenética velocidad de la transformación económica global.

La paradoja del período fue doble: por una parte, en el momento en que las relaciones mundiales se inclinaban hacia la agenda económica, del mismo modo en que el crecimiento económico se consolidaba en Asia, Chile y Japón no lograron capitalizar los frutos de una relación que habían cuidado por más de un siglo, tanto por la crisis estructural de la economía japonesa como por la arrolladora influencia de China que opacó crecientemente el otrora indiscutido lugar de Japón en Asia y en el mundo; por otra parte, al tiempo que Chile entró en una fase de estabilidad política postdictadura, Japón se hundió en una inestabilidad política que afectó seriamente su capacidad para cumplir con el plan estratégico bilateral que se había esbozado a comienzos de la década de 1990.

Una pregunta clave para entender esta paradoja es ¿por qué una potencia como Japón decide tener una relación estratégica con un país tan pequeño como Chile? y eventualmente ¿qué ocurre cuando

\footnotetext{
* Universidad de Santiago de Chile. Departamento de Historia. Santiago, Chile. Correo electrónico: cesar.ross@ usach.cl
} 
una potencia se acopla estratégicamente con un Estado más pequeño?

Obviamente las claves no están en el ámbito de los intereses, que por cierto lo hubo, sino que principalmente en el ámbito de los principios de las relaciones internacionales, especialmente en momentos en que estas quedan sujetas a estructuras complejas como las de doble asimetría.

Acuñé la categoría de doble asimetría hace unos 10 años y la expuse por primera vez en un artículo publicado por Foreign Affairs (Ross, 2006). De allí en adelante la he desarrollado y hecho más compleja (Ross, 2005) (2009) (2012)1. Además de aplicarla a casos relacionados con lo que he llamado asimetría hacia abajo (Ross \& Leiva, 2017). En este trabajo la aplico a un caso de asimetría hacia arriba, que, como he mencionado en las publicaciones aludidas, corresponden a las experiencias exitosas que Chile ha tenido especialmente con el Este de Asia.

La noción de asimetría proviene de la geometría, y alude a la falta de correspondencia exacta, en la disposición regular de las partes o puntos de un cuerpo o figura con relación a un centro, un eje o un plano. Esta idea prevalece del mismo modo en casi todas las otras ciencias que usan el concepto.

En economía, especialmente en el ámbito monetario, la categoría ha sido empleada para referirse a la fijación de las paridades entre monedas, donde suele usarse una de ellas como referencia. En algunos enfoques económicos heterodoxos, se ha trabajado intensamente acerca de la asimetría en la distribución del ingreso. Desde Karl Marx hasta Thomas Pikkety ${ }^{2}$ se ha podido argumentar y demostrar que la asimetría resulta regresiva, tanto porque se la ve como un antivalor (desigualdad) como porque se la ve como un indicador de ineficiencia en el desempeño económico. Esta idea también ha sido proyectada al ámbito internacional, para explicar las relaciones económicas entre los países y las diferencias de distribución de renta entre ellas, asociadas a factores inducidos por los actores más fuertes, de modo de generar diferencias y ventajas artificiales que explican centralmente el éxito de unos y el fracaso de los otros: en este tipo de línea argumental se encuentran trabajos como los de Vladimir I. Ulianov (1915), Fernando Cardoso y Enzo Faletto (1996) e Immanuel Wallerstein (1974), entre otros.

En el ámbito de la ciencia política, la idea (más que el concepto) ha sido usada respecto de la desigual concentración de poder en uno y otro lado de una relación, incluso considerando que los contenidos del poder han estado en proceso de reorganización, especialmente desde el punto de vista de los énfasis.

En el campo de las relaciones internacionales y de historia de las relaciones internacionales, el concepto adquiere el mismo sentido que en ciencia política, aunque con precisiones interesantes para este análisis. Las diferencias de poder establecen relaciones de dominación y subordinación, que la política internacional ha incorporado a sus análisis desde hace mucho tiempo.

Para el caso de Chile esta doble asimetría consiste en la relación simultánea que tiene el país, tanto con las principales economías del mundo como con aquellos -espacialmente los países vecinos- cuyo poder relativo es claramente menor al chileno. $\mathrm{La}$ asimetría hacia arriba ha redundado en sendos dividendos económicos, la asimetría hacia abajo, en tanto, ha devenido en relaciones que avanzan y se repliegan continuamente (Ross \& Leiva, 2017).

Respecto de la primera asimetría, asimetría hacia arriba, que también podría denominarse como asimetría virtuosa ${ }^{3}$, es factible puntualizar que el país logró establecer una relación pragmática (neorrealista), poniendo particular atención a su inserción internacional mediante tres formas de apertura: uni, bi y multilaterales, lo que reforzó el crecimiento económico chileno mediante dos fuentes principales, como son las exportaciones y la inversión extranjera directa. En una primera etapa (1975-1989), este proceso contó con buenas decisiones, buenas soluciones y un contexto político interno que impedía que los costos sociales de muchas de las medidas se tradujeran en una inestabilidad política capaz de revertir esas decisiones. En una segunda fase (1990-2016), los buenos resultados económicos asociados a la continuidad, ampliación y perfeccionamiento del modelo de inserción internacional reforzaron la legitimidad del proceso general y consolidaron la opción internacional de la estrategia chilena. Sin duda, esta última ha sido la etapa más brillante de la política exterior nacional hasta el presente, pues se logró institucionalizar, mediante acuerdos relevantes $\left(\mathrm{AAP}^{4}, \mathrm{ACE}^{5} \mathrm{y}\right.$ $\mathrm{TLC}^{6}$ ), los vínculos de Chile con las principales áreas económicas del mundo. A esta altura, mucho más que una opción económica, era una forma de estar en un mundo global, cuya naturaleza hacía que todas las agendas nacionales fueran, en último término, agendas internacionales. Después de 30 años, el país alcanzó una forma de vida (económica, 
tecnológica, política, social, cultural, etc.) cuya intensa vinculación con el mundo es irreversible. Esta relación asimétrica de Chile con actores más poderosos ha derivado en un reconocimiento internacional del país, expresado en ciertos indicadores que demuestran esta nueva posición, que ha reforzado crecientemente la capacidad relativa de negociación del país y ha dado fundamento a la ilusión de algunos respecto de la capacidad del país para ejercer liderazgo a nivel regional.

La segunda asimetría, asimetría hacia abajo, que también podría denominarse asimetría regresiva ${ }^{7}$, en donde Chile aparece como el país fuerte y otros actúan como los Estados débiles, está revestida de aspectos de mayor dificultad, debido a que aquí la interdependencia es compleja, por cuanto está sujeta a múltiples variables y está tamizada de una interpretación ideológica, en donde varios de los países vecinos a Chile asumen el rol histórico de "víctimas", en tanto actores ubicados al "sur" o en la "periferia" de la relación. Sin duda alguna, este es el tipo de asimetría que opera en la relación de Chile con sus vecinos del norte, Bolivia y Perú. La sola necesidad chilena de alimentar su crecimiento con energía limpia y barata, así como el imperativo de articular efectivamente los corredores bioceánicos, que permitan consolidar, físicamente, su proyecto de "país puente" entre las economías del Cono Sur de América y otras regiones económicas del mundo, especialmente el Este de Asia (Ross, 2004), impone redefinir las relaciones de asimetría hacia abajo, para transformarlas de su estado actual, de asimetrías regresivas al de asimetrías virtuosas. Esto supone, sin embargo, sustituir la definición de integración que ha prevalecido hasta ahora, donde a la integración se le ve como una meta maximalista ${ }^{8}$, para reemplazarla por otra, donde la integración sea vista como una herramienta puesta al servicio del desarrollo (Di Filippo, 2000).

En consecuencia, el principal desafío de la política exterior de Chile ya no es la continuidad, que fue ampliada y mejorada durante estos años de gobiernos democráticos, si no, conservando aquello, se deben reinventar estas otras relaciones, cuya interdependencia compleja obliga al país a formularse opciones que hasta aquí han estado fuera del análisis.

El objetivo general del artículo es elaborar y proponer una explicación al cierre del exitoso ciclo de relaciones entre Chile y Japón del período 1990-2007, mediante la implementación de una nueva metodología que combina la codificación de los contenidos de las memorias ministeriales, para reconstruir la agenda bilateral; y la jerarquización de las visitas bilaterales, destinado a determinar los patrones estructurales de la relación abordada.

La metodología de trabajo optó por el enfoque de la Teoría Fundamentada, proceso estratégico para gestionar y analizar los datos en una investigación para describir y explicar esos datos. Este proceso es generar teoría a partir de los datos procesados.

Las fuentes utilizadas en este artículo fueron útiles para del diseño teórico-metodológico y para la recolección y procesamiento de los datos. En lo primero se recurrió a las fuentes con que este autor elaboró su propia teoría respecto de la doble asimetría y acerca de política exterior en general y la bibliografía referida a Japón y las relaciones de Chile con Japón. En lo segundo, las subestimadas memorias del Ministerio de Relaciones Exteriores, usualmente leídas de manera literal, resultaron relevantes bajo la lupa de la metodología propuesta, ya que arrojaron un cúmulo de información relevante.

En cuanto a la estructura, este artículo está organizado en tres partes. La primera, titulada Los límites de la asimetría hacia arriba: la paradoja de las relaciones entre Chile y Japón, aborda los sucesos históricos en las relaciones entre ambos países en el período 1990-2001; la segunda parte, En búsqueda del patrón: lo que se podría ver, donde se expone la metodología para el análisis ulterior; y la tercera, El diálogo bilateral directo y el peso de lo que no se vio, que presenta los patrones que, a simple viste, parecían invisibles.

El artículo termina con las conclusiones y cierra con un anexo en el que se exponen aspectos claves de la metodología y de la base de datos en la que se sostienen los argumentos.

\section{Los límites de la asimetría hacia arriba: la paradoja de las relaciones entre Chile y Japón}

Como se ha planteado en la Introducción, quizá en ningún momento histórico, en este período, las relaciones entre Chile y Japón estuvieron tan cerca de convertirse en estratégicas, como a principio de los noventa. Si embargo, este esfuerzo se vio frustrado tanto por lo complejo del objetivo como por lo extemporáneo del modelo de asociación al que apelaba, más propio de la Guerra Fría. 
La paradoja del período planteó que en el momento en que las relaciones internacionales tendían a la supremacía de la agenda económica, al tiempo en que el crecimiento económico se consolidaba en Asia, Chile y Japón, ambos países no lograron capitalizar los frutos de una relación que habían cuidado por más de un siglo.

En lo específico, para todo este período las relaciones entre Chile y Japón estuvieron caracterizadas por cuatro factores clave: primero, la especificidad económica, que para muchos observadores parecía la dimensión casi exclusiva; segundo, la interdependencia simple, que operó entre ambos países, la que adquirió la forma de una asimetría virtuosa que, en síntesis, es un forma de integración comercial cooperativa sostenida por las exportaciones primarias de Chile (commodities) y por la importación de bienes manufacturados desde Japón, vale decir, en la complementación de nuestras fortalezas y en la supresión de nuestras debilidades. De allí el éxito que se ha logrado en ese ámbito y de allí también sus limitaciones; tercero, la estabilidad política de Chile como un dato crítico de su inserción internacional, lo que ha estado relacionado no solo con la continuidad democrática, sino que con la estabilidad de las reglas con las que se han hecho los cambios al mismo sistema político y económico; y cuarto, la inestabilidad política de Japón ${ }^{9 *}$ y su subsecuente repliegue internacional, el que también se debe a la mayor y creciente preponderancia de China, lo que ha tendido a reducir la presencia japonesa en la agenda internacional de Chile.

Estos factores se vieron tamizados por un contexto internacional específico, marcado por dos tipo de cambios. A nivel mundial, por las transformaciones derivadas del fin de la Guerra Fría y las crisis económicas de 1997 y 2001. A nivel asiático, el impacto específico de la Crisis de 1997 y el efecto estructural que ella tuvo en el ascenso de Chile y la pérdida de liderazgo de Japón.

\section{1.a. Fin de la Guerra Fría y Crisis de Burbuja a la Crisis Asiática (1990-1997)}

El período post-Guerra Fría constituyó un momento crítico para el debate historiográfico y político. El debate de entonces se preguntaba por ¿cuál sería la forma que tomaría nuestro mundo después de concluida esta fase en la que concluía la GF y, para muchos, la propia modernidad? Se abrió una etapa de transición muy dinámica en la que el patrón del conflicto internacional parecía dar paso a la asociación y complementación, sobre todo económica, entre vecinos e incluso entre antiguos adversarios, lo que comenzó a influir en el debate intelectual, el que había comenzado incluso antes (Fukuyama, 1989). En este escenario, sin embargo, Japón que había aprovechado tan bien las oportunidades económicas de la post-Guerra, se vio enfrentado a una "década perdida". La crisis económica de 1991-92 marcó el término de la llamada economía de burbuja (1980-90), asociada al incremento artificial de los precios en general y, especialmente, de los bienes raíces, a raíz de que los bancos nipones tomaron la decisión de invertir los superávits comerciales en tierra y edificios. Japón entró en una fase larga de recesión que se agravó con la crisis de 1997 y con las crisis políticas internas, todo ello afectó poderosamente su capacidad para desarrollar sus relaciones internacionales y para concretar el vínculo estratégico (tesis del puente), como el que se había propuesto con Chile.

\section{1.b. Crisis Asiática y los atentados del 9/11 (1997-2001)}

El segundo subperíodo (1997-2001) constituye un breve lapso entre dos crisis, desde la llamada crisis Asiática que comenzó en julio de 1997 hasta la crisis internacional derivada del ataque de septiembre 11 al World Trade Center y al Pentágono, lo que representó el ataque más relevante a Estados Unidos desde el comienzo del período histórico de su supremacía mundial post1945. Este evento, a mi juicio, puso en duda el pronóstico de Fukuyama respecto de la naturaleza irreversible de la globalización económica, bajo el enfoque neoliberal y el final de la predominancia del conflicto tanto en el sistema internacional como en el estudio de las relaciones internacionales, que hasta entonces había estado centrada en la tensión entre seguridad y amenaza.

En lo específico, la Crisis Asiática marcó una declinación estructural de la economía japonesa. Esta tendencia, que había sido presagiada en la etapa anterior (Thurow, 1992), se vio amplificada por las crisis políticas niponas que en parte explican el contexto en la que esta se originó y desarrolló. En los "felices 90" (Stiglitz, 2004) Japón no solo no logró capitalizar el nuevo escenario político y económico del mundo y de Asia, sino que se vio opacado por el ascenso arrollador de China. 
Por su parte, la crisis de 2001 (9/11) no hizo más que profundizar la tendencia que se había desatado en 1997, con el agravante de afectar la composición de la agenda económica que en la "feliz" década anterior parecía globalizarse irreversiblemente. En efecto, el fantasma de la Guerra Fría reapareció rápidamente, pero de la mano de la religión ${ }^{10}$, derivando en la mayor "securitización" de la agenda global (Buzan, Wæver, \& De Wilde, 1998), lo que no solo incrementó la incertidumbre originada en la amenaza de un nuevo terror global, a escala individual y no nuclear, sino que aumentó los costos de los negocios internacionales, con lo que las economías más eficientes -en el manejo de costos globales- resultaron aún más favorecidas. Otra vez China resultó ganadora de esta batalla.

El tercer subperíodo (2001-2007) describe el lapso desde la incertidumbre global derivada del 9/11 hasta la tardía certidumbre bilateral, alcanzada con la suscripción del Tratado de Libre Comercio bilateral, cuya firma se hizo en un momento en que otra vez la relación bilateral parecía eclipsada por una nueva crisis internacional.

A partir del 2001 (9/11) el escenario internacional se volvió más complejo para la política y la economía mundial. Los nuevos costos económicos del flete marítimo (incremento de los seguros y petróleo), la necesidad de garantizar la trazabilidad de los barcos, el incremento exponencial del precio internacional del petróleo, la caída estructural de la tasa de crecimiento económico de Estados Unidos (2001-2009) y la caída exponencial del consumo interno estadounidense, como resultado de la nueva y creciente inseguridad, activó una fase de recesión a partir de 2001. Para revertir esta situación el Congreso aprobó un paquete financiero de 15.000 millones de dólares para el sector aéreo, en tanto que el gobierno de Bush adelantó un recorte adicional de los impuestos para revitalizar el consumo. Estas medidas, sin embargo, no tuvieron el efecto esperado.

Pese a este escenario, los esfuerzos de los gobiernos de Chile y del empresariado de Chile y Japón dio frutos, y en 2004 el gobierno nipón aprobó reiniciar el proceso y el TLC finalmente se suscribió el 2007. Con este acuerdo se fortaleció el vínculo bilateral, pero en un momento en que la economía mundial entraba en una nueva crisis (2007-2008) relacionada con el colapso de la burbuja inmobiliaria de EE.UU., la que sería aprovechada por el ya sólido impulso de la economía China.
Cuando se cumplían 110 años de relaciones bilaterales y cuando se pensaba que, por fin, comenzaría una etapa de consolidación de este vínculo, devino la decepción. La crisis de 20072008 marcó un quiebre que más bien ha descrito una tendencia a la baja en el comercio y, quizá, en el lugar que estos países tienen para su contraparte.

\section{En búsqueda del patrón: lo que se podría ver}

Las ciencias sociales y políticas buscan elaborar generalizaciones de validez universal. En el caso de los estudios internacionales, sus generalizaciones están destinadas a comprender, explicar (Hollis \& Smith, 1990) e, idealmente, predecir los fenómenos internacionales, o sea aquellos que trascienden la realidad nacional y que involucra a dos o más países.

Este tipo de ejercicio analítico debe estar basado en descripciones pormenorizadas y rigurosas, elaboradas ad hoc o realizadas para otros efectos. Los datos derivados de estas descripciones permiten determinar patrones conductuales de actores y fenómenos internacionales (Jackson, 2016), de modo de crear una teoría que permita reducir la incertidumbre respecto del comportamiento del fenómeno estudiado en el corto y mediano plazo.

Desde un enfoque de carácter longitudinal, también es posible explicar el cambio como una consecuencia de identificar patrones estructurales $\mathrm{y}$, en consecuencia, determinar cómo se desarrolla la dinámica entre continuidad y cambio (North, 1993). Este tipo de análisis permitiría, incluso, predecir la conducta futura de actores y fenómenos, con un margen de error controlado y reducido.

El enfoque de la Teoría Fundamentada, presente dominantemente en las ciencias sociales y políticas, es un proceso estratégico para gestionar y analizar los datos en una investigación proporcionando formas conceptuales que sirven para describir y explicar esos datos. Este proceso de generar teoría a partir de los datos mediante una investigación social [y política] es el camino más adecuado para el descubrimiento de nuevas teorías basadas en deducciones lógico-conceptuales. La Teoría Fundamentada es, en síntesis, un proceso de generar teoría a partir de los datos mediante una investigación (Andréu, García-Nieto, \& Pérez, 2007).

El modelo siguiente debería generar información suficiente como para producir un tipo de 
teoría fundamentada respecto del comportamiento de las relaciones bilaterales entre Chile y Japón, a partir del análisis de la variable "visita" y de la variable "codificación de agenda". Ambas dan cuenta de comportamientos estructurales que no solo suplen, sino que permiten confrontar los discursos respecto de esta relación.

\subsection{La idea de patrones en la mirada histórica $^{11}$}

La Historia (ciencia) está comprometida en el esfuerzo mayor de situar al observador en el plano artificial de escrutar la realidad en una perspectiva longitudinal, que supone capturar -al mismo tiempo- la continuidad y el cambio de un tiempo pasado (historia). En esta mirada tensionada por dualidad temporal, la gran tarea de la Historia es captar este doble movimiento de la historia, para describirlo y explicarlo.

Los cambios, como hitos reconocibles, expresan tanto los puntos de inflexión a partir de los cuales cambia la tendencia precedente como el repertorio de transformaciones que acreditan que el pasado está siendo desplazado por un nuevo orden. El prestigio de estos momentos, sin embargo, se forma en el largo plazo historiográfico, hasta que un cierto consenso llega a una unanimidad en cuanto atribuirle su valor de inflexión en el proceso mayor del tiempo.

La continuidad, por su parte, representa el peso residual de un pasado aún más remoto y el peso estructural de los fenómenos mayores y enraizados en el proceso examinado. En este sentido, por su naturaleza inmanente, la continuidad (regularidad) (Topolsky, 1985) tiende a pasar relativamente inadvertida, no obstante que también contiene rasgos de transformación y, en consecuencia, en esta dimensión también se puede y debe advertir las mutaciones en lo que parece pétreo y que resulta menos evidente. Sin embargo, representa una de las cuestiones más caras de la Historia y constituye uno de sus principales desafíos. Las regularidades históricas son la clave para entender el largo plazo y para comprender el significado de los cambios.

En la perspectiva de la llamada Escuela de los Annales, la profundidad del largo plazo es la dimensión donde subyace la gran historia y que, conectada con el acontecer superficial, permite comprender aquello que constituye las claves del proceso histórico, sea este de una temporalidad remota o de lo que se ha llamado Historia reciente o del tiempo presente.

Apoyados por la mirada de largo plazo, aunque no fuere en el sentido estricto que la Escuela de los Annales le dio a esta categoría, es posible mirar el pasado planteándole problemas para resolver y preguntas para solucionar.

En definitiva, al identificar patrones podemos contar con una recurrencia o regularidad que facilite la formulación de conjeturas e hipótesis más confiables, podemos determinar conductas estructurales y, en cierto modo, ver aquello que antes parecía menos visible.

Desde el punto de vista de lo que interesa a este análisis, los silenciosos patrones de continuidad y cambio en las relaciones entre Chile y Japón están invisibilizados por el impacto de una década de intensa actividad económica mundial, donde parecía que las relaciones comerciales, las inversiones internacionales y la actividad financiera global eran casi la única fuente de explicaciones para las relaciones internacionales, incluso en un vínculo como este, cuya historia (Ross, 2004, 2005, 2009 , 2017) y singularidad bien podía advertir a los observadores que probablemente había mucho más que la racionalidad cognitivo-instrumental que expresaban las series estadísticas para elaborar explicaciones de suyo complejas. Esta relación debe entenderse desde dicha dimensión, pero también desde una racionalidad simbólica, basada en los atributos blandos del vínculo y expresada en categorías como la lealtad, la confianza, la buena fe y la reciprocidad. Todo esto, se podría afirmar, estuvo en la base de cómo el Comité Empresarial Chile-Japón entendió su condición de existencia (Ross, 2001) (2002).

Por lo anterior, es posible afirmar que las relaciones entre Chile y Japón han tenido su principal fortaleza en lo que quizá sea el rasgo más distintivo de la diplomacia, la capacidad para establecer diálogos y entendimientos de cara a cara, incluso en los momentos en que los conflictos entre los principios e intereses de sus políticas exteriores parecían presagiar desde impasses hasta rupturas totales.

La historia de Chile y Japón es una de conversaciones suaves, de confianzas profundas construidas en el largo plazo, de simbolismos ${ }^{12}$ y de esfuerzos prolongados por mostrarse respeto y consideración. Todo esto ocurrió en conversaciones 
entre diplomáticos ${ }^{13}$ y paradiplomáticos, entre gobiernos que diferían (Ross, 2014) y coincidían ideológicamente (Ross, 2007). Por ello no se podría elaborar una explicación de su último período histórico desatendiendo quizá a la principal fuente que informa de este vínculo. Lo que podríamos llamar la dimensión "blanda" de sus relaciones.

Sin embargo, las "conversaciones" bilaterales, entendidas como los actos de comunicación entre ambos países, no solo están registradas en la transcripción de reuniones o en la proliferación de documentos oficiales ${ }^{14}$ y discursos, muchas veces limitados por las formalidades, sino que por una multiplicidad de gestos, que más que residir en la documentación, han quedado capturados en los registros que dan cuenta de los hechos que la sustentan. Con Japón la clave no está en lo que se ha dicho, sino que en lo que se ha hecho. En este contexto la agenda real y las visitas son la fuente principal para conocer y comprender este período clave en que, como nunca en nuestra historia, estuvimos al borde de asociarnos estratégicamente con la segunda potencia del mundo y sin que ello implicara subordinación política y sometimiento ideológico.

\subsection{Agenda bilateral: codificación del diálogo}

El registro escrito del diálogo bilateral suele quedar fijado en una serie anual denominada Memoria para el caso chileno y Libro Azul para el caso japonés. En estos volúmenes se registra la versión oficial del vínculo, lo que constituye una limitación para la interpretación, pero no para la recopilación de datos, pues si bien estos textos pueden omitir datos sensibles, también suelen incluir mucha otra información que permite, sobre todo en el análisis longitudinal, reconstruir de manera muy pormenorizada el curso de la relación analizada.

En el libro anual queda el rastro de personas, temas, hitos, fechas y lugares. Estos datos permiten reconstruir una trama que puesta en una serie temporal cuantificada, nos facilitan tener una visión de ritmos, ciclos, momentos de expansión y contracción, todo ello configura un panorama mucho más complejo y completo de la lectura de una relación bilateral.

Procesar todo este cúmulo de información, sobre todo cuando se trabaja con los registros anuales de ambos países, demanda articular dos dimensiones: por un lado, la identificación de cuestiones relevantes y coyunturales; y por otro, la reconstrucción de comportamientos de más largo plazo que detectar la existencia de patrones, cuya persistencia dé cuenta de las continuidades y de los cambios que se estuviesen ocurriendo y que fueran relativamente imperceptibles a la observación contingente.

Desde el punto de vista de los procedimientos, la codificación realizada aquí no difiere mucho de cualquier otra codificación. Se emplea una lista de temas generales, presentes en toda agenda de relaciones internacionales y referida a relaciones económicas, políticas, sociales, culturales, de seguridad, etc. Con esos casilleros de entrada, se procede a realizar una primera identificación y selección de temas en cada anuario (Memoria y Libro Azul), en la sección correspondiente a Japón y a Chile, respectivamente. En una segunda etapa, y dentro de cada casillero, se detectan temas específicos, los que van ampliando y hacen complejas la caracterización y comprensión de cada uno de estos temas generales.

Hecho lo anterior, se despliegan estos en una matriz que sitúe temas generales y temas específicos, en orden vertical, en una columna al extremo izquierdo (eje); y que ubique los años en una fila en el extremo superior, ordenados de izquierda a derecha (abscisa). Así diseñada, la matriz contiene todos los registros por año (suma vertical descendente) y todos los registros por temas y subtemas (suma de izquierda a derecha). Cada mención recibe un punto, de modo que se puede contar las menciones en ambos sentidos, con lo que se puede tener tanto una mirada longitudinal (dinámica del vínculo) como de su estructura (distribución por temas y subtemas).

Para el período sujeto a este análisis (1990-2007), la Memoria del Ministerio de Relaciones Exteriores de Chile registró 385 menciones y el Libro Azul de Japón contabilizó 92, todo esto permite aseverar que de ese cúmulo es posible identificar patrones y coyunturas de manera consistente.

En términos generales, la agenda de diálogo bilateral acredita que entre 1990 y 1997 hubo un ciclo de expansión de los contactos, el que sufrió una contracción entre 1993 y 1995. A contar de 1995 y hasta 1997 los contactos se intensificaron, correspondiendo al lapso en que se propuso la alianza estratégica del puente y se trabajó intensamente en que esta diera sus frutos para el año del 
centenario, pero en dicho año se detonó la Crisis Asiática y su impacto fue significativo. Es clave observar que hasta el 2000 la caída en la interacción demostró que este evento generó un efecto inmovilizador entre ambos países. Sin embargo, a partir de dicho momento la interacción bilateral tendió a restablecerse en una expansión menor a la fase precedente que se vio eclipsada por un evento de escala mayor, como fue el 9/11. A partir de dicho momento, y pese a que a contar de 2004 se retomó la negociación para el TLC ${ }^{15}$, la declinación de los contactos disminuyó ostensiblemente. Suscrito el acuerdo, las interacciones siguieron cayendo, casi en la misma medida que China ganaba terreno en el comercio y en la agenda global en detrimento del lugar que antes había ocupado Japón (Gráfico 1).

La desagregación de la agenda bilateral del período 1990-2007, a base de fuentes japonesas ${ }^{16}$, demuestra que desde la perspectiva japonesa la relación con Chile pasó por dos $\operatorname{ciclos}^{17}$, cuya frontera fue la Crisis Asiática. A diferencia de la perspectiva chilena, para Japón el ciclo de mayor actividad fue el segundo, nítidamente estimulado por las negociaciones del Tratado de Libre Comercio, pese a que dicho proceso tuvo un dinamismo muy errático, pasando por una fase de impulso, el que fue seguido por una latencia de inacción que finalmente se rompió en 2004 cuando se retomó la negociación hasta concluirse con la suscripción del acuerdo en 2007 (Gráfico 2).

A la expansión de la actividad política asociada a la propuesta japonesa por suscribir un acuerdo con Chile (dimensión política internacional), decisión tomada en 1999, le siguió una caída que coincide con el 9/11, recuperando y superando su nivel anterior hacia 2003, pero volviendo a caer al año siguiente, lo que se reanima con motivo del periodo de la negociación del acuerdo aludido, en el período 2004-2007.

Por su parte, la dimensión relacionada con las relaciones económicas tendió a incrementarse, como una forma de enfrentar la contracción derivada de la crisis de seguridad del 9/11, la que tendió a contraerse en la medida que la negociación reforzaba la certidumbre bilateral a que conducía el acuerdo.

El intercambio cultural y la cooperación se mantuvieron en niveles muy bajos, al punto de tener escasa significación como para la caracterización de estas relaciones, más allá de constatar que en este período -como en otros- su rol fue muy secundario.

Por su parte, la desagregación de la agenda bilateral basados en fuentes chilenas ${ }^{18}$ y por sus

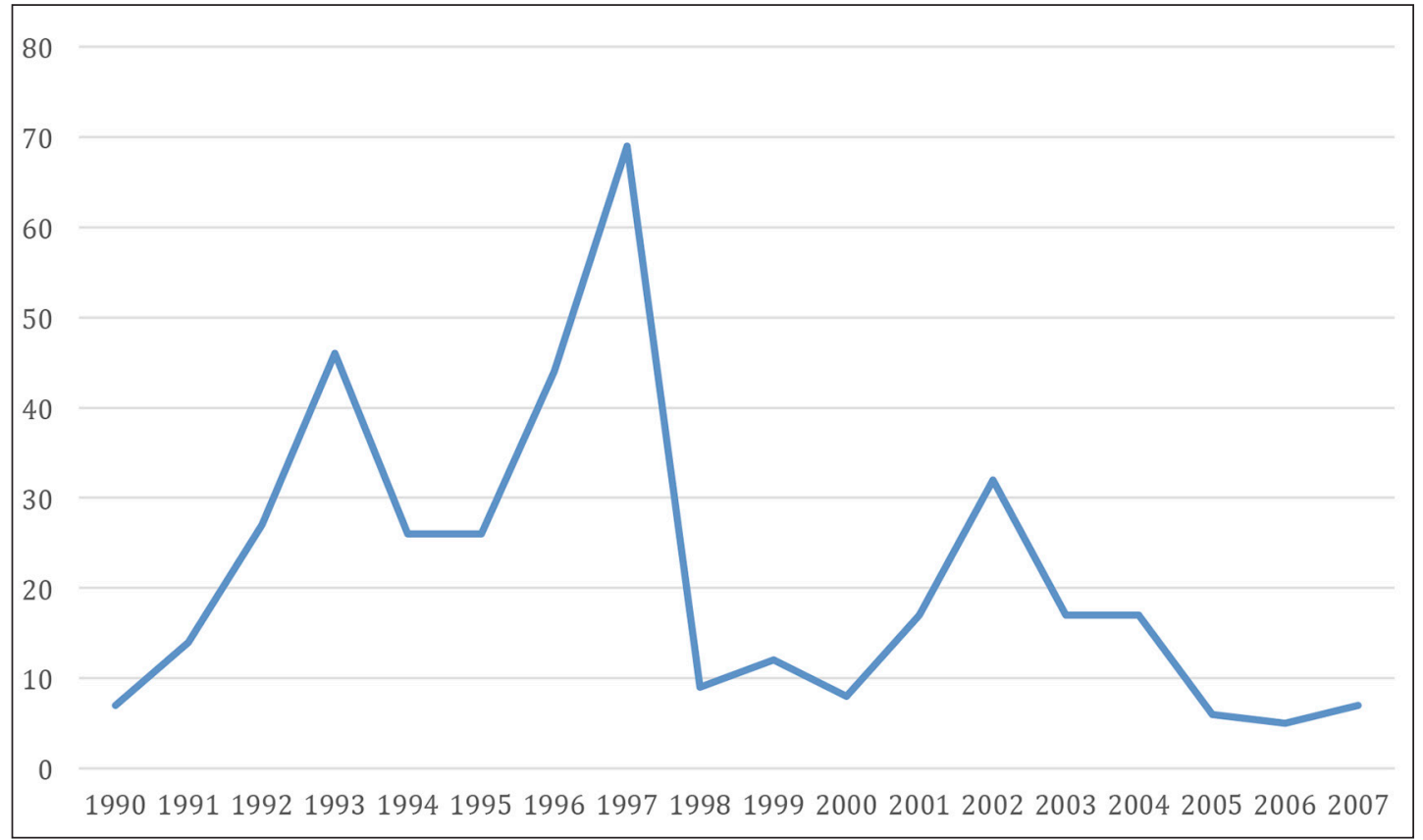

Gráfico 1. Chile y Japón, 1990-2007: Codificación Agenda Bilateral.

(Fuentes de Chile y Japón: Número de registros). 


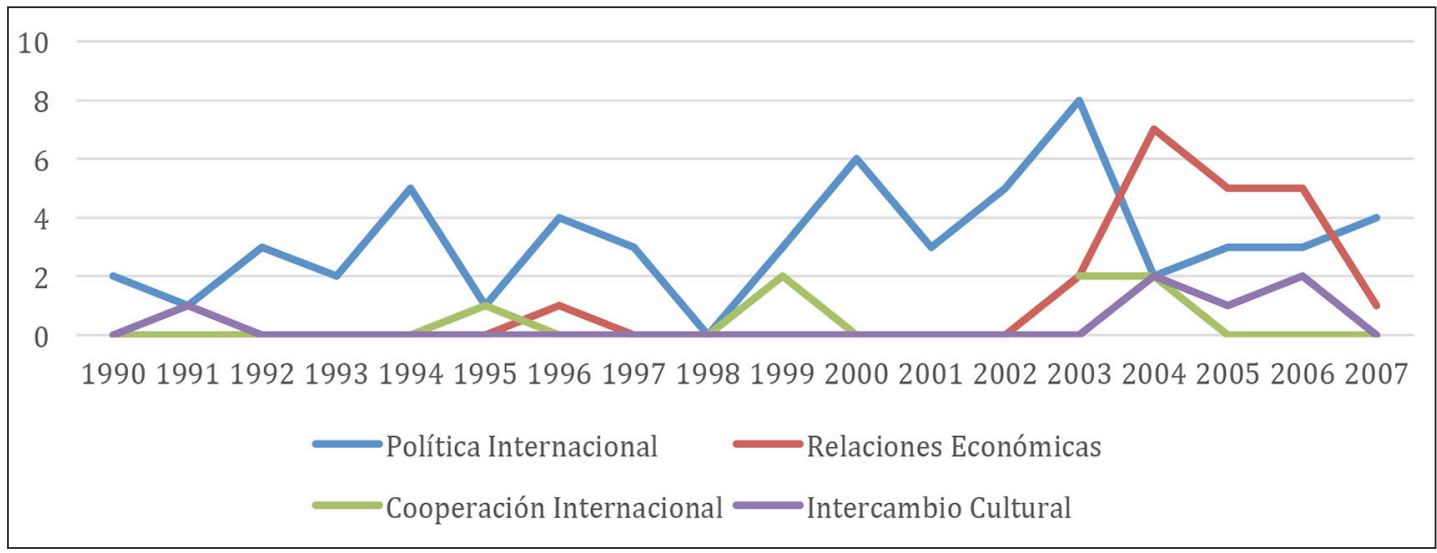

Gráfico 2. Chile y Japón, 1990-2007: Agenda bilateral. (Fuentes japonesas: $\mathrm{N}^{\mathrm{o}}$ de registros por dimensiones).

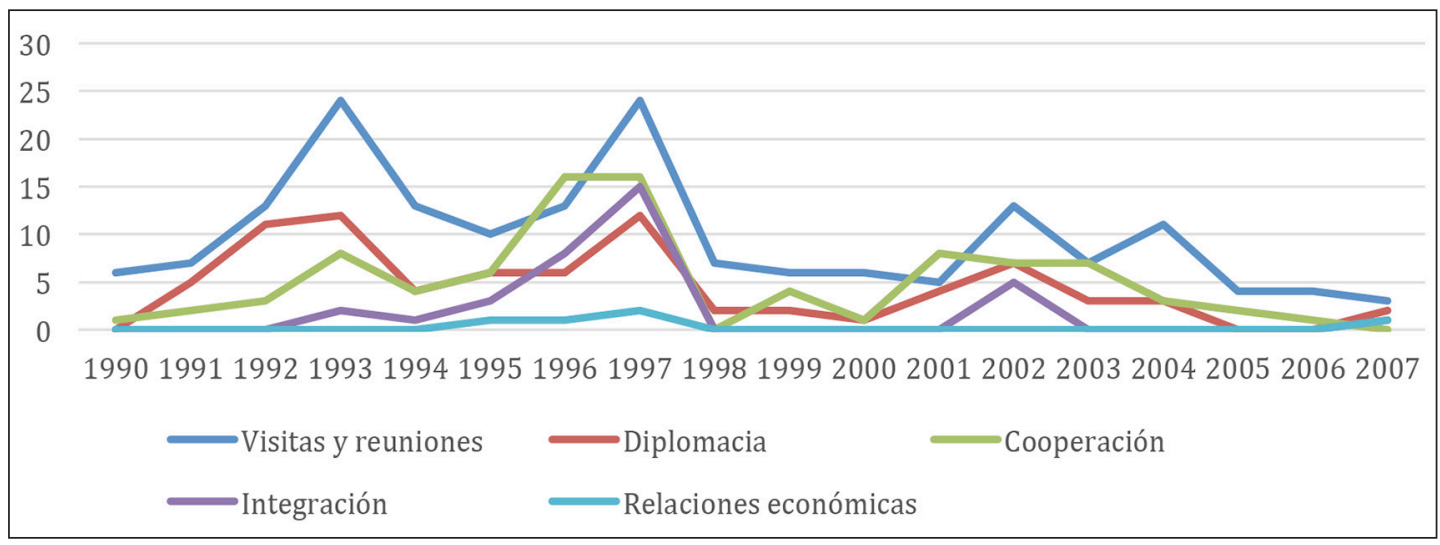

Gráfico 3. Chile y Japón, 1990-2007: Agenda bilateral.

(Fuentes chilenas: $\mathrm{N}^{\mathrm{o}}$ de registros por dimensiones).

principales dimensiones, permite ver que hubo importantes esfuerzos diplomáticos, o sea de política internacional, que sustentaron el vínculo. Al mismo tiempo, se aprecia que la interacción centrada en lo económico fue muy baja.

Como la principal dimensión, las visitas y reuniones expresan la misma forma descrita por la curva general de la Agenda, vale decir, demuestra los impactos de las coyunturas descritas, incluso exhibe una caída entre 2006 y 2007, pese a que en dicho año se realizaron las reuniones finales del proceso de negociación del TLC (Gráfico 3).

Paradójicamente, la dimensión económica consignada como casi la única de estas relaciones, tuvo un nivel muy bajo. Es posible que ello se debiera a que se trataba de una materia tratada más en ámbitos privados, aunque su bajo nivel también podría ser una clave para comprender por qué las opciones de una alianza estratégica entre ambos se hubieran diluido.

La cooperación, la actividad diplomática propiamente tal y las iniciativas de integración, todas claves en el proceso de implementar un proyecto de alianza estratégica, sufrieron el impacto de la Crisis Asiática y no volvieron a su nivel de precrisis después de 1998.

Esta es una perspectiva que hasta ahora era invisible sin la elaboración de este análisis y, en consecuencia, un aspecto en el que no era posible enfocarse.

Al mismo tiempo, es difícil explicarse por qué en años tan críticos para alcanzar un objetivo tan difícil de lograr y tan relevante, el esfuerzo dedicado a ello pareciera tan insuficiente.

Una explicación posible, que coincidiría con lo que ocurrió con la política exterior de Chile 
(Ross, 2012), podría estar basada en la idea que Chile creció y se desarrolló en estos años, pero su élite no alcanzó a adaptarse y ha refundar el modelo de inserción internacional, con el fin de adaptarlo al nuevo estatus internacional del país. Por extensión, es posible que los tomadores de decisión de entonces no hubieran tenido plena conciencia de la envergadura de lo que estaba en juego.

\subsection{Visitas internacionales: categorización según jerarquía}

En el ámbito diplomático, sea cual fuere la acepción que diéramos a esta categoría ${ }^{19}$, la comunicación entre Estados y entre actores no estatales suele estar constituida por un conjunto de medios o herramientas destinados a hacer más eficiente la circulación de los mensajes y, por extensión, a mejorar la efectividad del diálogo.

Como se trata de contactos que buscan ayudar a satisfacer objetivos de política internacional, las comunicaciones escritas y las visitas han sido, a lo largo de la historia, los mecanismos más ampliamente empleados (Berridge \& James, 2003). La comunicación escrita, en forma de cartas y notas reversales ${ }^{20}$, y las visitas, en el marco de encuentros multilaterales $\mathrm{y}$, preferentemente, en reuniones realizadas ex profeso, evidencian los intereses de los involucrados.

La comunicación escrita tiene la fortaleza de constituir compromisos, en tanto las contrapartes siempre pueden basarse en las comunicaciones anteriores para reclamar compromisos y cumplimientos futuros.

La visita, si bien está basada en una comunicación oral, y en consecuencia no necesariamente deriva en un texto que pueda adquirir el rango que se indica en el párrafo anterior, permite un acercamiento personal que usualmente facilita el proceso de negociación y de toma de decisiones.

Por otro lado, si bien una visita acelera los acontecimientos, también es muy sensible a factores subjetivos de orden intercultural (Galluccio, 2014) e interpersonal (Braithwaite \& Schrodt, 2014), lo que implica que los malos entendidos pueden derivar en una tensión o en un impasse que implique un retroceso en la materia que se estaba tratando. Con todo, las visitas tienen un enorme valor para zanjar asuntos relevantes, en un contexto que puede ir de las conversaciones protocolares a otras denominadas informales y reservadas, donde se puede hablar con sinceridad y cuyo propósito es arribar a una decisión ${ }^{21}$.

La visita, en consecuencia, tiene un alto valor en las relaciones internacionales, en tanto es la mayor demostración de interés por la contraparte y por los asuntos que les involucran. En este sentido, el rango de los visitantes, el tiempo de la visita, así como los resultados concretos que se buscan con la visita, son directamente proporcionales a la valoración que se hace de la contraparte. Pese a esta función e importancia, la bibliografía especializada no ha resuelto cómo categorizarlas, lo que impide otorgarle algún valor cualitativo y cuantitativo, más allá del sentido común o la repetición de juicios sin fundamento empírico.

Un examen longitudinal de las visitas entre dos y más actores, permite realizar una evaluación más compleja y dinámica de sus relaciones en un lapso determinado, así como facilita la interpretación que se pueda hacer de los acontecimientos situados en un contexto histórico específico.

Basados en una metodología elaborada ex profeso acerca de este análisis (Ross, 2017), es posible observar que las visitas bilaterales del período 1990-2007 estuvieron marcadas por la circulación de autoridades de variada jerarquía, pero dominadas por aquellas con menor capacidad decisoria, sobre todo considerando el plan de alianza estratégica que se planteó entre ambos países a contar de 1994.

Para efectos de esta exposición se ha incluido en anexo la explicación detallada (ver Anexo), pero en síntesis se ha asignado a cada visita un puntaje diferenciado de acuerdo con el rango de cada sujeto. Así, las máximas autoridades de un Estado (Jefes de Estado y Jefes de Gobierno) tienen un rango equivalente a 100 puntos; las visitas inmediatamente inferiores o de segundo nivel (secretarios de Estado, ministros, presidentes de organizaciones estatales y no estatales de nivel nacional) tienen un rango equivalente a 80 puntos; las visitas de tercer nivel (secretarios de Estado adjuntos (viceministros o subsecretarios, autoridades de unidades territoriales mayores, como gobernadores e intendentes, senadores nacionales, embajadores, presidentes de organizaciones estatales y no estatales a nivel de unidades territoriales mayores.) tienen un rango equivalente a 60 puntos; las visitas de cuarto nivel (autoridades de unidades territoriales intermedias, como gobernadores y autoridades provinciales, ministros consejeros, cónsules, diputados de unidades 
territoriales intermedias, presidentes de organizaciones estatales y no estatales a nivel de unidades territoriales intermedias) tienen un rango equivalente a 40 puntos; las visitas de quinto nivel (autoridades de unidades territoriales menores, como alcaldes e intendentes, presidentes de organizaciones estatales y no estatales a nivel de unidades territoriales menores, rectores universidades nacionales) tienen un rango equivalente a 20 puntos; y las visitas de sexto nivel (corresponden a los integrantes de comitivas, diferente a las autoridades identificadas en la ubicación de $1^{\circ}$ a $5^{\circ}$ del ranking) tienen un rango equivalente a 3 puntos. Este ejercicio metodológico se puede observar en Gráfico 4, donde se evidencia el rango de las visita japonesas a Chile durante el proceso estudiado.

Sin embargo, cuando las visitas se ponderan en función de su jerarquía ${ }^{22}$, se revela una nueva

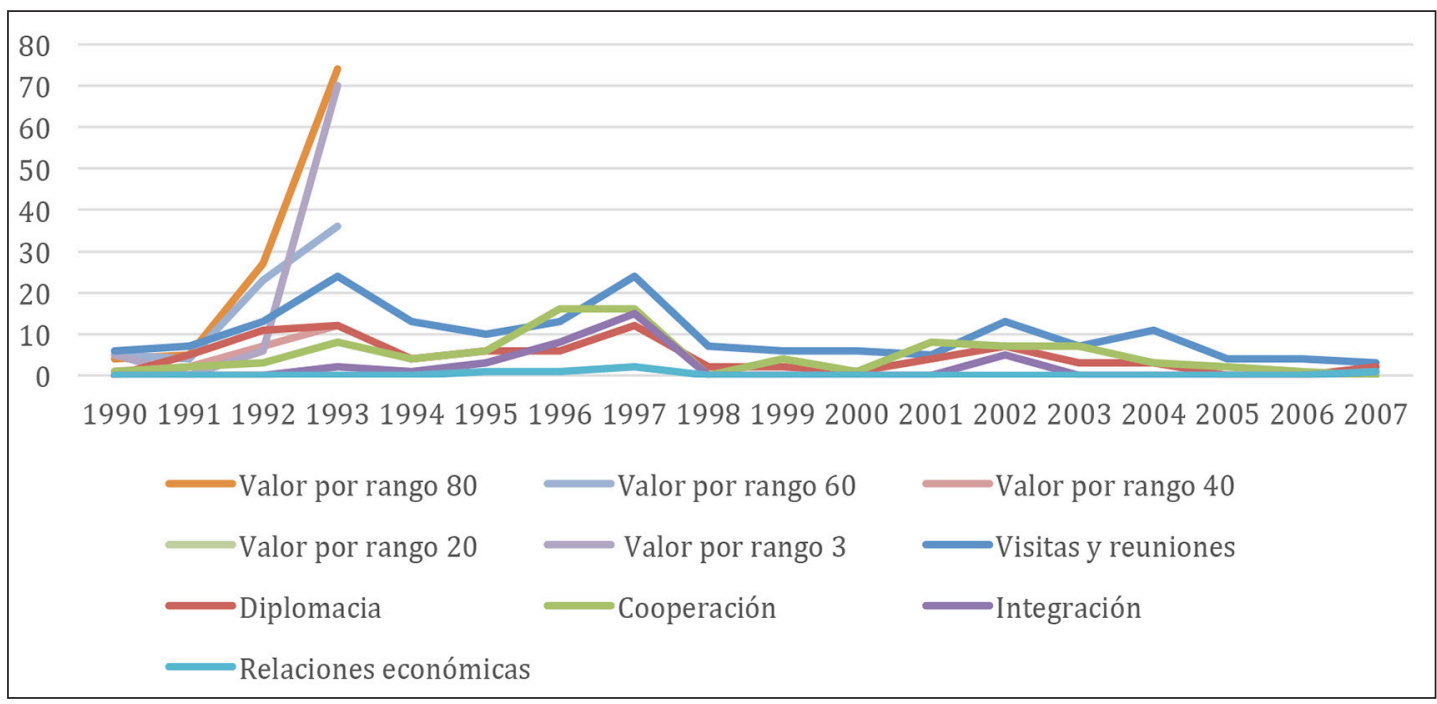

Gráfico 4. Chile y Japón, 1990-2007: visitas por rango.

(Datos en bruto: sin ponderar).

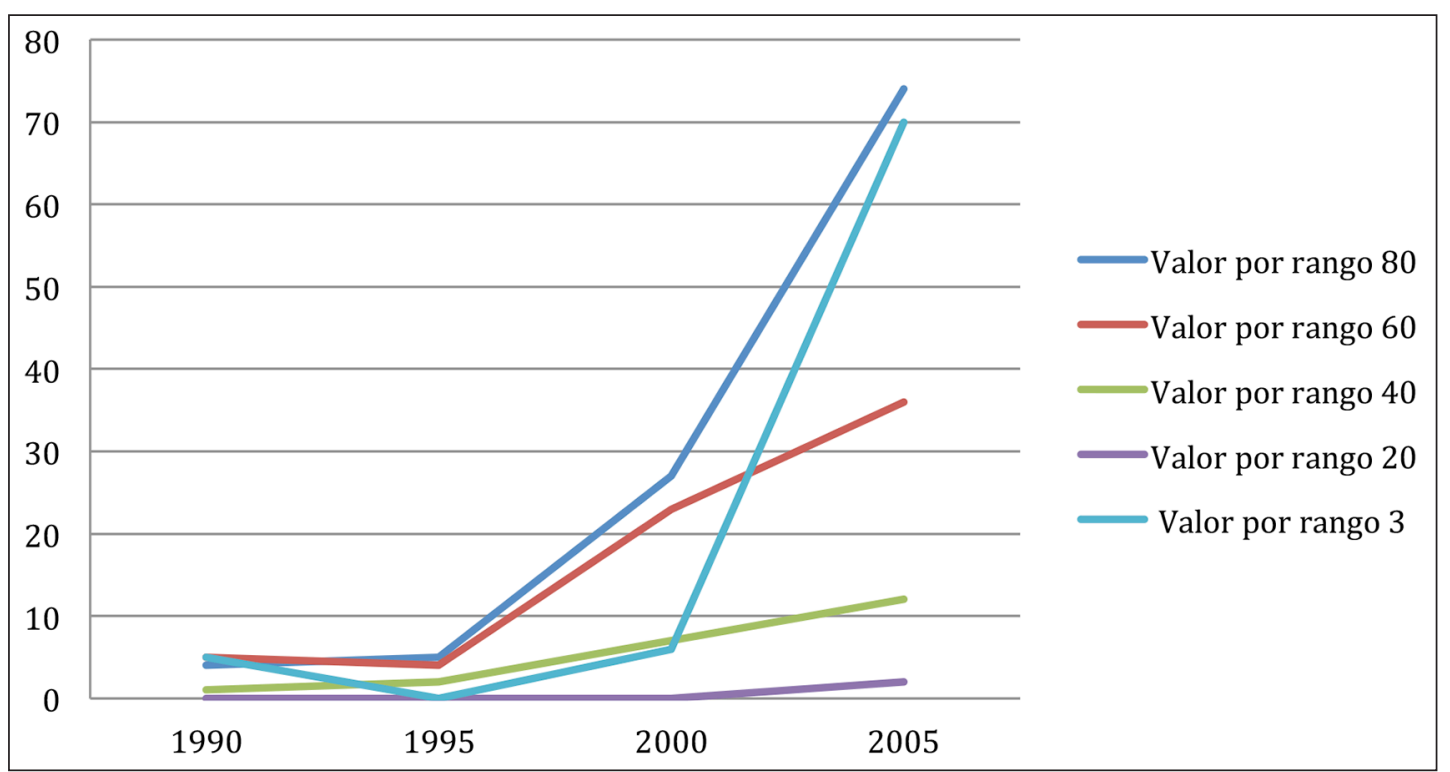

Gráfico 5. Chile y Japón, 1990-2007: visitas por rango.

(Ponderadas). 
versión de ellas. Los visitantes de rango $80^{23}$ se multiplican de manera exponencial a partir de 1995 sin espacio a dudas, lo mismo que ocurre con los de rango 3. Al mismo tiempo que los de nivel intermedio se incrementan de manera moderada, para los de rango $60^{24}$ y de manera leve para los de rango $40^{25}$.

A juzgar por toda la información examinada para este estudio, el Gráfico 5 demuestra que hubo visitas de alto nivel que impulsaron relaciones de mejor calidad (más amplias y profundas), pero estos esfuerzos no fueron complementados de manera robusta y sostenida por los niveles intermedios donde se produce la implementación y decisiones de carácter técnico, con el fin de conseguir que lo que se visualiza y decide en la cúspide se logre cristalizar como políticas públicas de los Estados.

Por ahora no tenemos evidencia para explicar por qué ocurrió este fenómeno, que hasta ahora resultó tan invisible a la discusión académica, como interesante para ser considerado como posible fuente de explicaciones. Esta afirmación se basa en el volumen de datos examinados y en el carácter estructural de esta conducta internacional, lo que permite plantear que no se trata de una excepción, sino que de un patrón.

\section{El diálogo bilateral directo $y$ el peso de lo que no se vio}

El diálogo bilateral directo es la combinación analítica de cruzar dos dimensiones: de qué y quiénes hablan (codificación de la agenda) y en qué circunstancias hablan (visitas). En el cruce de estas dimensiones surgen ciertas claves que hasta aquí habían permanecido invisibles para los análisis hechos para esta relación bilateral y que constituyen orientaciones analíticas para otros casos.

Por una parte, el restablecimiento de la democracia en Chile y fortalecimiento general de las relaciones bilaterales, impulsadas por la política de reinserción internacional del gobierno de Patricio Aylwin y reforzadas por el Comité Empresarial Chile-Japón.

Por otra, en 1994 tuvimos una oportunidad inédita en nuestra historia: conformar una alianza estratégica con la segunda economía del mundo, que además lo era por ser líder científico, tecnológico e industrial, todo ello había alcanzado por ser líder en educación de calidad. Todos, factores críticos para que Chile diera un paso cualitativo relevante en su proyecto de país.

En tercer lugar, este propósito bilateral, declarado oficialmente por las autoridades más altas del mundo político y empresarial de ambos países, se tropezó con coyunturas adversas de escala nacional (efecto estructural de la crisis de burbuja, crisis asiática) y global (9/11 y crisis Subprime de 2007/08), las que dificultaron alcanzar el desafío propuesto.

En cuarto, pese a la adversidad descrita, las autoridades de ambos países lograron materializar sus esfuerzos en términos de alcanzar los acuerdos que podrían permitir este logro, sin embargo esas gestiones no se vieron coronadas por los resultados esperados.

En quinto lugar y frente a la pregunta de por qué no se logró lo que se esperaba, se puede plantear que hasta aquí no solo se habían hecho conjeturas generales. Ahora, basadas en dos metodologías analíticas elaboradas ex profeso se puede plantear una nueva hipótesis que ilumina este período, nos sugiere cómo examinar otros casos y nos da pistas respecto de cómo actuar en el futuro.

Nuestra hipótesis de salida plantea que el subvalorado efecto de la crisis asiática de 1997 en el curso del acuerdo de alianza estratégica suscrito en 1994 se convirtió en una coyuntura crítica que puso en jaque el proyecto y que los esfuerzos posteriores por suscribir un TLC no lograron revertir.

Al mismo tiempo, la insuficiente relación entre la mayor actividad japonesa para impulsar el diálogo con Chile y la menor actividad chilena frente a su contraparte. Adicionalmente, un grado de inconsistencia, hasta ahora no identificada por la bibliografía dedicada a este tema, del diálogo bilateral en cuanto a la importancia que cada país dio a las dimensiones que componían la agenda bilateral.

En lo esencial, la inconsistencia radicó en cuatro aspectos. Primero, una inconsistencia referida al grado de adhesión hacia la relación, que demuestra que durante el primer ciclo (1990-1997) Chile fue más activo que Japón, así como durante el segundo (1998-2007) Japón mostró más dinamismo que Chile. Segundo, una inconsistencia referida a la diacronía de los énfasis, que exhibe que para todo el período se observa que Japón dio más importancia a la dimensión de la política internacional, mientras que Chile le dio una importancia menor, la que decreció notoriamente después de la crisis 
de 1997. Tercero, otra inconsistencia de carácter diacrónico, revela que mientras Japón le dio un bajo énfasis a la dimensión económica hasta $2003^{26}$, Chile fue más activo en ella durante el primer ciclo, decayendo en el segundo pese a la negociación para el TLC. Cuarto, una inconsistencia de tipo "un solo espejo" 27 , en que a propósito del TLC dio una gran importancia a la dimensión cultural, lo que no tuvo en Chile una contraparte correspondiente.

Adicional y finalmente, la insuficiente interacción entre autoridades de rango medio (entre rango 30 y 60) y los subsecuentes efectos que esto tuvo en el desarrollo de la alianza estratégica, cuya implementación radicaba principalmente en sujetos pertenecientes a estos niveles, terminó por hacer inviable la materialización de un propósito que no solo requería mantener, sino que redoblar esfuerzos y equipos.

\section{Conclusiones}

Como se planteó en la Introducción a este trabajo, la paradoja del período fue doble. En el momento en que las relaciones mundiales se inclinaban hacia la agenda económica, del mismo modo en que el crecimiento económico se consolidaba en Asia, Chile y Japón, cuya relación disfrutaba de la asimetría virtuosa, no lograron capitalizar los frutos de una relación que habían cuidado por más de un siglo. Esta frustración tensiona la noción de asimetría hacia arriba, por cuanto exhibe los límites de su desempeño en el caso de relaciones bilaterales que mayores dividendos podía ofrecerle al modelo propuesto. Las claves de este fracaso podrían darle la razón a quienes han estado del lado de las tesis clásicas respecto de la asimetría en relaciones internacionales, como vínculos necesariamente asociados a una distribución desigual de los dividendos y en donde el actor más fuerte toma mayores beneficios y el actor más débil los menores. Sin embargo, una análisis centrado en la agenda y en las visitas bilaterales, de manera pormenorizada y ponderada, como se ha expuesto anteriormente, revela una nueva visión de esta historia y permite reinterpretar un proceso que hasta ahora podría haberse leído de manera lineal, a base de modelos de causalidad predeterminados por el tipo de teorías a que hemos hecho mención en la Introducción, referidas a las relaciones asimétricas entre actores internacionales, y a las que hemos aludido al comienzo de las conclusiones. El detalle del análisis vertido en este trabajo permite reafirmar la utilidad de la categoría asimetría hacia arriba, pero también detecta los límites de su utilización en un caso ilustrativo como es abordado por este estudio.

En este contexto teórico e histórico, el año 1994 es clave porque entonces ambos países se plantearon convertirse en socios estratégicos, lo que sería una oportunidad inédita en la historia de Chile. Conformar una alianza de esta naturaleza con la segunda economía del mundo, que además lo era por poseer un nítido liderazgo científico, tecnológico e industrial, todo esto se había alcanzado por ser líder en educación de calidad. Este carácter no solo había sido destacado en múltiples estudios que aludían al "milagro japonés", sino que al efecto que dicho proceso había generado en el Este de Asia, en un modelo que Kename Akamatsu había bautizado como el de los Ganzos voladores (Kojima, 2000) y que había sido calificado por el Informe del Banco Mundial del año anterior como "el milagro del Asia Oriental". Se trató, pues, de un contexto de alto optimismo, donde todo parecía presagiar que nos subiríamos al "caballo ganador" en una estrategia que prometía obrar en Chile el mismo efecto que ya había causado en Asia, lo que implicaba una oportunidad inmejorable para superar el modelo de país primario-exportador, por lo que bien podría hablarse de una oportunidad histórica e inédita.

Este propósito bilateral, declarado oficial y públicamente por las más altas autoridades del mundo político y empresarial de ambos países, tropezó con coyunturas adversas de escala nacional (efecto estructural de la crisis de burbuja, crisis asiática) y global (9/11 y crisis Subprime de 2007/08), las que complicaron el desafío propuesto. En cierta medida, el proyecto no prosperó porque la dinámica de los fenómenos internacionales mencionados no permitió que se desarrollaran y mucho menos se implementaran los planes que llevaran a dicho logro. Como país articulador, entre Japón (y más allá Asia) y América del Sur, Chile debía dar un salto muy significativo en servicios e infraestructura. Hoy se podría afirmar que se logró lo primero, pero no lo segundo. Sin la concurrencia simultánea de ambos aspectos, no se logró salir del punto de partida.

Pese a la adversidad descrita, las autoridades de ambos países lograron materializar sus esfuerzos 
en términos de alcanzar los acuerdos para crear el marco de reglas que podría permitir este logro, sin embargo esas gestiones no se vieron recompensadas con los resultados esperados. Es más, tantos y tan buenos esfuerzos sin sus correlativos logros produjo frustración, casi paralelamente al efecto de "seducción" que a esos mismos empresarios, diplomáticos y técnicos gubernamentales les generó China, con su crecimiento arrollador y su diplomacia omnipresente.

Las explicaciones respecto de este fracaso han sido escasas e incompletas, al punto que no habían logrado satisfacer del todo a los especialistas. Básicamente por haber sido elaboradas con informaciones agregadas y con nociones preconcebidas, como las tesis asociadas a las teorías antes mencionadas de las relaciones asimétricas. Por ello se ha planteado que más que tesis se trató de conjeturas generales. Ahora, sin embargo, y a base de dos metodologías analíticas elaboradas ex profeso, se puede plantear una nueva idea que puede mejorar la comprensión de este fenómeno y, por extensión, de este período. Ello, además, eventualmente nos podría permitir examinar otros casos y nos podría dar pistas respecto de cómo actuar en el futuro.
El análisis realizado hasta aquí permite identificar tres grupos de explicaciones. Primero, el subvalorado efecto que causó la crisis asiática de 1997 en la materialización del acuerdo de alianza estratégica de 1994, debido a que esta crisis puso en jaque una alianza que los esfuerzos posteriores por suscribir un TLC no lograron revertir, e incluso puso en duda la utilidad de que el país se hubiera centrado tanto en Asia y en Japón. Segundo, la insuficiente relación entre la mayor actividad japonesa para impulsar el diálogo con Chile y la menor actividad chilena frente a su contraparte, lo que se vio agravado por la inconsistencia del diálogo bilateral, en cuanto a la diferenciada importancia que cada país dio a las dimensiones que componían la agenda bilateral. Tercero, la insuficiente interacción entre autoridades de nivel medio (entre los rangos 30 y 60) y los subsecuentes efectos que esto tuvo en el desarrollo de la alianza estratégica, cuya implementación radicaba principalmente en sujetos pertenecientes a estos niveles.

En este contexto, la mirada longitudinal, la búsqueda de patrones y la implementación de metodologías ad hoc, finalmente abren la puerta para reinterpretar un proceso que fue tan relevante como invisible.

\section{Anexo}

\section{Criterios de asignación de puntaje}

1.1. Se asigna puntaje a las visitas para ponderar su importancia y, por extensión, asignar una estimación cuantitativa a la presencia (valor analógico) de cada una de ellas.

1.2. En cada visita, se asigna puntaje a cada integrante (PI) de la comitiva, en función de las autoridades identificadas entre el 1 y 5 del ranking. La suma de estos puntajes constituye en puntaje de la visita (PV).

1.3. A cada integrante de la comitiva, diferentes a las autoridades indicadas, se le asignará 1 punto.

1.4. La asignación de puntaje por tramo de ranking se realiza de manera simple (sumatoria bruta de puntajes).

1.5. La asignación de puntaje agregado se hace mediante la ponderación de los puntajes acumulados de cada tramo de ranking.

1.6. El puntaje total de una visita (suma de la valorización de cada integrante de una comitiva) se multiplica por un factor (2) por cada día de la visita (DV) multiplicando las horas y dividiendo por 24. En los casos en donde no se especifique el número de días, se asumirá por defecto que se trató de una visita de 1 día.

1.7. Al puntaje total de una visita (suma de la valorización de cada integrante de una comitiva) se asigna un puntaje extra, en función de los logros concretos (LC) de ella: suscripción de instrumentos (Tratados: 100; Acuerdos: 50; Convenios: 25; Protocolos: 15; Memorándum de Entendimiento: 10; y Cartas de Intención: 5). 


\section{Tabla de puntaje}

\begin{tabular}{|c|c|c|c|}
\hline Ranking & Jerarquía & $\begin{array}{l}\text { Rango } \\
\text { (Puntaje) }\end{array}$ & $\begin{array}{l}\text { Ponderación } \\
\qquad(\%)\end{array}$ \\
\hline 1 & $\begin{array}{l}\text { - Jefes de Estado } \\
\text { - Jefes de Gobierno }\end{array}$ & 100 & 33 \\
\hline 2 & $\begin{array}{l}\text { - Secretarios de Estado (ministros) } \\
\text { - Presidentes de organizaciones estatales y no estatales de nivel nacional. }\end{array}$ & 80 & 27 \\
\hline 3 & $\begin{array}{l}\text { - Secretarios de Estado adjuntos (viceministros o subsecretarios) } \\
\text { - Autoridades de unidades territoriales mayores (gobernadores, intendentes, etc.) } \\
\text { - Senadores nacionales } \\
\text { - Embajadores } \\
\text { - Presidentes de organizaciones estatales y no estatales a nivel de unidades terri- } \\
\text { toriales mayores. }\end{array}$ & 60 & 20 \\
\hline 4 & $\begin{array}{l}\text { - Autoridades de unidades territoriales intermedias (gobernadores, autoridad } \\
\text { - Mrovincial, etc.). } \\
\text { - Cónsul } \\
\text { - Diputados (unidades territoriales intermedias). } \\
\text { - Presidentes de organizaciones estatales y no estatales a nivel de unidades terri- } \\
\text { toriales intermedias. }\end{array}$ & 40 & 13 \\
\hline 5 & $\begin{array}{l}\text { - Autoridades de unidades territoriales menores (alcaldes, intendentes, etc.) } \\
\text { - Presidentes de organizaciones estatales y no estatales a nivel de unidades terri- } \\
\text { toriales menores. } \\
\text { - Rectores universidades nacionales }\end{array}$ & 20 & 7 \\
\hline 6 & $\begin{array}{l}\text { - Por cada integrante de comitiva, diferente a las autoridades identificadas en la } \\
\text { ubicación de } 1 \text { a } 5 \text { del ranking. }\end{array}$ & 3 & 1 \\
\hline N/A & - Ponderación agregada: curva general & N/A & 100 \\
\hline
\end{tabular}

\section{Cálculo puntaje total de una visita}

$$
\text { Puntaje Agregado: }(\mathrm{PV})+(2 * \mathrm{DV})+\mathrm{LC}
$$

\section{Referencias Citadas}

Andréu, J.; García-Nieto, A. \& Pérez, M.

2007 Evolución de la Teoría Fundamentada como técnica de análisis cualitativo. Madrid, España: Centro de Investigaciones Sociológicas.

Bernal-Meza, R.

2016 Contemporary Latin American thinking on International Relations: theoretical, conceptual and methodological contributions. 59 (1), 1-32.

Berridge, G. \& James, A.

2003 A dictionary of Diplomacy. London, UK: Palgrave.

Braithwaite, D., \& Schrodt, P.

2014 Engaging Theories in Interpersonal Communication: Multiple Perspectives. London, UK: Sage.

Buzan, B.; Wæver, O. \& De Wilde, J.

1998 Security: A New Framework for Analysis. Boulder, USA: Portada Barry Buzan, Ole Wæver, Jaap de Wilde Lynne Rienner Publishers.
Cardoso, F. \& Faletto, E.

1996 Dependencia y desarrollo en América Latina: ensayo de interpretación sociológica. Ciudad de México, México: Siglo XXI.

Chatham House

s/f Chatham House Rule. Retrieved 2017 йил 6-marzo from Chatham House: https://www.chathamhouse.org/about/ chatham-house-rule

Dammert, L.

2012 Fear and Crime in Latin America: Redefining StateSociety Relations. Routledge.

Di Filippo, A. Y.

2000 Integración Regional, Desarrollo y Equidad. Ciudad de México, México: Siglo XXI-CEPAL.

Fukuyama, F.

1989 The End of History? The National Interest, 3-18. 
Galluccio, M.

2014 Handbook of International Negotiation: Interpersonal, Intercultural, and Diplomatic Perspectives. Bruselas, Bélgica: Springer.

Glaser, B., \& Strauss, A.

1967 The discovery of grounded theory: strategies for qualitative research. New York, USA: Aldine Publishing Company.

Hollis, M., \& Smith, S.

1990 Explaning and Understanding International Relations. Oxford, UK: Oxford University Press.

Jackson, $\mathrm{P}$.

2016 The Conduct of Inquirity in International Relations. London, UK: Routledge.

Kojima, K.

2000 The "flying geese" model of Asian Economic development: origin, theoretical extensions, and regional policy implications, Tokyo: American Committee on Asian Economic Studies (ACAES). Journal of Asian Economics (11), 375-401.

Lacoste, $\mathrm{P}$.

Argentina, Chile y sus vecinos (Vol. II). Mendoza, Argentina: Caviar Bleu.

North, D.

1993 Instituciones, Cambio Institucional y Desempeño Económico. Ciudad de México, México: Fondo de Cultura Económica.

Ross, C.

2017 Patent No. 268.546. Chile.

Ross, C.

2005 "Chile en la doble asimetría: Ensayo sobre la política internacional". Si Somos Americanos, Revista de Estudios Transfronterizos, III (3), 109-139.

Ross, C.

2007 Chile y Japón: 1973-1989 de la incertidumbre a la alianza estratégica. Santiago, Chile: LOM ediciones.

Ross, C.

2002 "Chile y Japón: la agenda de la alianza realista, 19741989”. Diplomacia (91), 5-19.

Ross, C.

2014 "Chile y Japón durante los mil días de Allende, 19701973: El camino lateral”. Universum, 29 (2), 277-290.

Ross, C.

2006 "Chile: los desafíos de la política exterior de Michel Bachelet”. Foreign Affairs en español, 6 (2).
Ross, C.

2001 "El Comité Empresarial Chile-Japón: de la liturgia al libre comercio, 1979-1999". Diplomacia (86), 89-111.

Ross, C.

2004 "El Este de Asia y el Cono Sur de América: ¿hacia un nuevo modelo de integración?". In C. Ross, Chile y APEC 2004: al encuentro de una oportunidad (pp. 145-169). Iquique, Chile: Universidad Arturo Prat.

Ross, C.

2016 йил 14-enero En Estudis de l'Àsia Oriental. Retrieved 2017 йил 6-marzo from América Latina y Asia Oriental: ¿Una oportunidad para la asimetría virtuosa?: http:// asiaoriental.blogs.uoc.edu/2015/12/10/autor-convidat-cesarross-relacions-america-llatina-i-asia-oriental/

Ross, C.

2009 "India: La agenda permanente de su política exterior". Revista Política y Estrategia (114), 119-148.

Ross, C.

2009 "Los Desafíos de la Política Exterior Chilena 20102014". Le Monde Diplomatique, X (102).

Ross, C.

2012 "Los Desafíos de la Política Exterior Chilena 20102014". In M. Artaza, \& C. Ross, Política Exterior de Chile, 1990-2009: Del aislamiento a la integración global (Tomo I) (pp. 853-880). Santiago: RIL Editores/USACH.

Ross, C., \& Leiva, S.

2017 "La política de Chile hacia Bolivia, 1990-2009: ni coordinación política, ni cooperación económica”. Estudios Políticos (50), 17-41.

Ross, C., \& Montaner, G.

2017 La agenda de los estudios de seguridad post 9/11: ¿de qué y quiénes hablan? 12 (2).

Stiglitz, J.

2004 Los felices 90. La semilla de la destrucción. Ciudad de México, México: Taurus.

Thurow, L.

1992 La guerra del siglo XXI: la batalla económica que se avecina entre Japón, Europa y Estados Unidos. Buenos Aires, Argentina: Vergara.

Topolsky, J.

1985 Metodología de la Historia. Madrid, España: Cátedra.

Ulianov, V.

1915 El Imperialismo, la Fase Superior del Capitalismo. Santiago, Chile: Quimantú.

Wallerstein, I.

1974 El moderno sistema mundial. Ciudad de México, México: Siglo XXI.

\section{Notas}

1 Otro autor que se ha referido a esta categoría de doble asimetría ha sido Raúl Bernal Meza (2016).

2 Desde El Capital (1867) hasta El Capital en el Siglo XXI (2014).

3 He acuñado la expresión de asimetría virtuosa como una metáfora para calificar la relación entre, al menos, dos actores cuyo poder es asimétrico, pero que logran establecer un vínculo de "suma variable", o sea, uno en donde ambos logran verse beneficiados. En Ross (2016, 2012).

4 AAP: Acuerdos de Alcance Parcial; PSTA: Partial Scope Trade Agreement.
5 ACE: Acuerdo de Complementación Económica; ECA: Economic Complementation Agreement.

6 TLC: Tratado de Libre Comercio; FTA: Free Trade Agreement.

7 Se refiere a aquella asimetría que redunda en un perjuicio para el actor más débil, cuya interacción redunda en un desempeño crítico que, pese a estar sujeto a avances y retrocesos, en la suma total siempre culmina en un retroceso.

8 Cuya negociación está casi siempre sujeta a una lógica de suma cero y en donde el compromiso de los Estados ha sido más retórico que político. Ross, César (2005), Argentina y 
Chile: los desafíos de la integración en tiempos de crisis (Lacoste, 2005).

$9 \quad 1990$ y 2007 hubo 10 primer ministros de los cuales 8 dimitieron, uno murió en ejercicio (Keizō Obuchi) y solo uno terminó su período (Jun'ichirō Koizumi).

10 Esta dimensión se volvió dominante en el debate académico, lo que reforzó la percepción de que esta era la principal fuente de la amenaza, sin perjuicio de que para América Latina era entonces y sigue siendo la insurgencia revolucionaria, aunque en fase de declinación, y el crimen organizado en una de ascenso. Dammer, Lucía (2012), Fear and Crime in Latin America: Redefining StateSociety Relations (Routledge Studies in Latin American Politics); Ross, C., \& Montaner, G. (2017). La agenda de los estudios de seguridad post 9/11: ¿de qué y quiénes hablan? 12 (2).

11 Esta es una cuestión mayor que no se pretende ni debatir exhaustivamente y mucho menos resolver aquí.

12 Tras servir en la marina chilena, el crucero Esmeralda fue vendido a Japón. En 1895 llegó a la isla y fue renombrado como Izumi, donde participó en la guerra contra China y en la guerra ruso-japonesa de 1905 , teniendo una destacada participación en la batalla de Tsushima. Otro gesto simbólico fue que en 1997, con motivo del Centenario de Amistad, el Buque Escuela Esmeralda transportó una gran bandera japonesa que el gobierno de Chile donó para conmemorar esta importante celebración.

13 Desplegada por Chile desde el nombramiento de Carlos Morla Vicuña, nombrado en 1897, hasta nuestros días.

14 Notas, oficios y télex, como ha sido la norma para el caso de Chile para todo el período precedente.

15 Que se había acordado elaborar en 1999, en el marco de una reunión del Comité Empresarial Chile-Japón.

16 Principalmente el llamado Libro Azul, editado por MOFA (Ministry of Foreign Affairs) del gobierno de Japón y fuentes provenientes de información oficial de la Embajada de Japón.

17 El primero se desarrolló entre 1990 y 1997, y el segundo entre 1998 y 2007.

18 Exclusivamente, la Memoria anual del Ministerio de Relaciones Exteriores de Chile, para el período 1990-2007.
19 Por ejemplo: diplomacia estatal, paradiplomacia, diplomacia de los pueblos, diplomacia pública, diplomacia de actores no estatales y otras.

20 Las notas reversales, notas paralelas o notas idénticas son un tipo de notas diplomáticas. Normalmente se utilizan para concertar algún entendimiento entre dos países. Son dos notas, una de propuesta y otra de respuesta y aceptación. La segunda transcribe textualmente la primera. En ambas se manifiesta que, una vez recibida la nota de respuesta con la aceptación, la materia constituirá un acuerdo entre los países. Por lo general estas notas entran en vigor en la fecha de la respuesta, aunque es posible fijar una fecha de entrada en vigencia posterior. Las notas reversales también pueden ser una forma simplificada de prestación del consentimiento de un tratado internacional. Mediante el intercambio de notas reversales los Estados firmantes deciden si quieren ser parte o no de un tratado firmado.

21 Bajo un esquema que suele ser asimilado a la reconocida regla Chatham House, de hablar con toda sinceridad, pero bajo reserva. Ver Chatham House. (s/f). Chatham House Rule. Retrieved 6 de marzo de 2017 from Chatham House: https://www.chathamhouse.org/about/chatham-house-rule

22 O sea, cuando se calcula en función de los parámetros complejos de la visita, como en los productos que ella genera. Ver anexo de este trabajo.

23 Rango 80: secretarios de Estado (ministros), presidentes de organizaciones estatales y no estatales de nivel nacional.

24 Rango 60: secretarios de Estado adjuntos (viceministros o subsecretarios); autoridades de unidades territoriales mayores (gobernadores, intendentes, etc.); senadores nacionales; embajadores; presidentes de organizaciones estatales y no estatales a nivel de unidades territoriales mayores.

25 Rango 40: autoridad provincial, etc.); ministros consejeros; cónsul; diputados (unidades territoriales intermedias); presidentes de organizaciones estatales y no estatales a nivel de unidades territoriales intermedias.

26 Año a partir del cual esta dimensión creció al ritmo de las negociaciones por el TLC bilateral.

27 Un solo espejo refleja a quien se pone frente a él, pero no implica la reciprocidad del "espejo doble". 
ANDROS IMPRESORES

wWw.androsimpresores.cl 